Tropical Journal of Pharmaceutical Research September 2015; 14 (9): 1659-1666

ISSN: 1596-5996 (print); 1596-9827 (electronic)

(C) Pharmacotherapy Group, Faculty of Pharmacy, University of Benin, Benin City, 300001 Nigeria.

All rights reserved.

Available online at http://www.tjpr.org

Original Research Article

http://dx.doi.org/10.4314/tjpr.v14i9.16

\title{
Double-layer Tablets of Lornoxicam: Validation of Quantification Method, In vitro Dissolution and Kinetic Modelling
}

\author{
Ümit Gönüllü*, Pınar Gürpınar and Melike Üner \\ Istanbul University, Faculty of Pharmacy, Department of Pharmaceutical Technology, Beyazit, Istanbul 34116, Turkey
}

*For correspondence: Email: ecz_gonullu@yahoo.com; Tel: +90 212 4400000/13507; Fax: +90 2124400252

Received: 18 March 2015

Revised accepted: 22 July 2015

\begin{abstract}
Purpose: To formulate double-layer tablets of lornoxicam (LRX) prepared by direct compression method and evaluate their physical and drug release characteristics.

Methods: The outer layer of tablets, composed of microcrystalline cellulose (MCC), starch and lactose, incorporated tan initial or prompt dose of the drug $(4 \mathrm{mg})$ for immediate release. Hydroxypropyl methylcellulose (HPMC), polyvinylpyrrolidone (PVP K90) and carbomer, in varying concentrations, were used to prepare the tablet cores for sustained drug delivery. Weight variation, dimensions, hardness, tensile strength, friability and disintegration time of the tablets were evaluated. Drug release from double-layer tablets as well as kinetic models of drug release were determined after validating the method used for the quantification of the drug. The analytical method for quantification of LRX by UV spectroscopy was validated and verified for linearity, intra-day and inter-day precision, accuracy, recovery and specifity.

Results: Tablet cores based on HPMC and HPMC:PVP K90 mixture displayed better compression and flow properties (good and fair to passable) than those formulated with PVP K90 and carbomer (poor). Satisfactory results were obtained from all the tablet formulations met compendial requirements. The slowest drug release rate was obtained with tablet cores based on PVP K90 $\left(1.21 \mathrm{mg} \% . \mathrm{h}^{-1}\right)$. Drug release followed Higuchi kinetic model and the tablet cores released drug by diffusion/polymer relaxation or diffusion/erosion.

Conclusion: Double-layer tablet formulation of lornoxicam based on HPMC or HPMC-PVP mixture is suitable for the treatment of inflammatory and painful conditions.
\end{abstract}

Keywords: Lornoxicam, Controlled release, Double-layer tablets, Non-steroidal antiinflammatory drug, Oral delivery

Tropical Journal of Pharmaceutical Research is indexed by Science Citation Index (SciSearch), Scopus, International Pharmaceutical Abstract, Chemical Abstracts, Embase, Index Copernicus, EBSCO, African Index Medicus, JournalSeek, Journal Citation Reports/Science Edition, Directory of Open Access Journals (DOAJ), African Journal Online, Bioline International, Open-J-Gate and Pharmacy Abstracts

\section{INTRODUCTION}

Controlled drug delivery systems are commonly used in therapy due to their various advantages over conventional dosage forms [1,2]. These systems meet specific therapeutic needs for various diseases. They delay release of drugs to maintain their plasma levels without a rapid onset of action. However, an initial dose should be released in the shortest time possible to relieve the symptoms of the disease in the case of some drugs including nonsteroidal antiinflammatory drugs (NSAIDs), antihypertensive, antihistaminic agents. Subsequently, drug effect should also be prolonged for some hours to optimize therapy [3]. A combination of a fast release pulse with slow release pattern could allow for an easier and more flexible optimization. 
Double-layer and multilayer tablets have been developed to achieve biphasic release of drugs to obtain quick followed by slow drug release patterns [4]. A tablet core providing sustained drug release which is coated with a fastdisintegrating outer layer by compression describes a double-layer tablet $[5,6]$. This kind of system leads to a maximum relief quickly via the initial burst of the coating layer. Drug release is followed by a sustained release phase to avoid repeated administration. It is also possible to produce this system by conventional methods including direct compression method which is more acceptable by the industry.

Lornoxicam (LRX) is a NSAID from oxicam family which has analgesic, anti-inflammatory and antipyretic properties. Its mean plasma half-life has been reported as 3-4 $h[7,8]$. LRX was thought to display its effects by inhibition of cyclooxygenase (COX) isoenzymes and thus to inhibit prostaglandin synthesis from arachidonic acid. LRX is used as an alternative drug to opioid analgesics or as a supportive medicament in the treatment of postoperative pains. Its analgesic activity is comparable to those of opioids. Peak plasma concentration of LRX is reached in $2 \mathrm{~h}$ after oral administration. It is administered as 2-3 divided doses daily.

The aim of this study was to design LRX doublelayer tablets composed of a outer layer and core containing $4 \mathrm{mg}$ initial dose and $12 \mathrm{mg}$ maintaining dose, respectively. Thus, the bioavailability of LRX would be able to increase with double-layer tablets. Patient compliance could be improved when possible side effects of LRX could be minimized. For this purpose, compression characteristics and physical properties of double-layer tablets were investigated.

\section{EXPERIMENTAL}

\section{Materials}

Lornoxicam (LRX) was kindly provided from Abdi İbrahim İlaç A.Ş. (Turkey). Carbomer (Carbopol ${ }^{\circledR}$ 971P NF) was obtained from Lubrizol (U.S.A.). HPMC (Methocel ${ }^{\circledR}$ K15 Premium EP) and Starch $\AA 1500$ were thankfully presented by Colorcon (England). PVP K90 (Povidone ${ }^{\circledR}$ K90) was purchased from Sigma-Aldrich (Germany) Lactose anhydrous (DMV, The Netherlands), Avicel Type $\mathrm{PH}-102$ (Selectchemie AG, Switzerland) and magnesium stearate (Prever, Italy) were thankfully provided from Liba Laboratuarları A.Ş. (Turkey). All other chemicals were of analytical grade.

\section{Preparation of double-layer tablets}

The composition of $250 \mathrm{mg}$ lornoxicam doublelayer tablets are shown in Table 1. One hundred milligram tablet cores containing $12 \mathrm{mg}$ LRX were compressed using a hydrolic press (Yeniyurt, Turkey) equipped with $7.9 \mathrm{~mm}$ diameter flat punch under $13790 \mathrm{kPa}$ force. They were coated with an outer layer containing the initial dose of LRX (4 mg). Then double-layer tablets containing tablet cores and $150 \mathrm{mg}$ outer layer were compressed using a $10 \mathrm{~mm}$ flat puch under $13790 \mathrm{kPa}$ force. Thus, the total LRX content of double-layer tablets were $16 \mathrm{mg}$.

\section{Physical characterization of tablets}

Carr's index $(\mathrm{Cl})$ (compessibility \%) and Hausner ratio of powders composing tablet cores and outer layer of double-layer tablets each before compression were determined $[9,10]$.

Table 1: Composition (\%) of double-layer tablets

\begin{tabular}{|c|c|c|c|c|c|c|c|c|c|}
\hline \multirow{3}{*}{$\begin{array}{l}\text { Tablet } \\
\text { ingredient }\end{array}$} & \multicolumn{9}{|c|}{ Double-layer tablet (250 mg) } \\
\hline & \multirow{2}{*}{$\begin{array}{c}\text { Outer layer } \\
(\% \text { in } 150 \text { mg) }\end{array}$} & \multicolumn{8}{|c|}{ Tablet core (\% in $100 \mathrm{mg}$ ) } \\
\hline & & $\begin{array}{c}\text { core } \\
\text { HPMC-1 }\end{array}$ & $\begin{array}{c}\text { core } \\
\text { HPMC-2 }\end{array}$ & $\begin{array}{l}\text { core } \\
\text { PVP-1 }\end{array}$ & $\begin{array}{l}\text { Core } \\
\text { PVP-2 }\end{array}$ & $\begin{array}{l}\text { Core } \\
\text { Ca-1 }\end{array}$ & $\begin{array}{l}\text { core } \\
\text { Ca-2 }\end{array}$ & $\begin{array}{c}\text { core } \\
\text { HPMC-PVP-1 }\end{array}$ & $\begin{array}{c}\text { core } \\
\text { HPMC-PVP-2 }\end{array}$ \\
\hline LRX & 2.67 & 12 & 12 & 12 & 12 & 12 & 12 & 12 & 12 \\
\hline HPMC & - & 15 & 20 & - & - & - & - & 10 & 15 \\
\hline PVP K90 & - & - & - & 5 & 10 & - & - & 5 & 5 \\
\hline Carbomer & - & - & - & - & - & 15 & 20 & - & - \\
\hline Avicel & 40.67 & 73 & 68 & 83 & 78 & 73 & 68 & 73 & 68 \\
\hline Starch & 10 & - & - & - & - & - & - & - & - \\
\hline Lactose & 46.67 & - & - & - & - & - & - & - & - \\
\hline
\end{tabular}

Magnesium stearate $(0.1 \%)$ was added to both layers of the tablets 
For this purpose, $10 \mathrm{~g}$ powder was poured freely into a $25 \mathrm{~mL}$ measuring cylinder and bulk volume $\left(V_{B}\right)$ was determined. Packed volume $\left(V_{P}\right)$ was obtained by tapping the powder 1250 times in a packed density apparatus (Erweka SVM 202, Germany). Thus, $\mathrm{Cl}$ and Hausner ratio of samples were calculated using the following equations via bulk $\left(D_{B}\right)$ and packed $\left(D_{P}\right)$ densities:

$D_{B}=10 / V_{B}$

$D_{P}=10 / V_{P}$

$C I=\left[D_{P}-D_{B} / D_{P}\right] \times 100$

Hausner ratio $=D_{P} / D_{B}$

Several parameters were also determined for physical characterization of tablets $[9,10]$. Weight variation, friability \%, hardness and in vitro release characteristics were determined in tablet cores and double-layer tablets. Swelling and erosion behaviours of tablet cores, and disintegration time of double-layer tablets were determined. For this purpose, 20 tablets were used for determination of weight variation using a balance (Denver Instrument). Friability \% was determined by using 20 tablets in an Erweka TA220 friabilitor (Germany) for $4 \mathrm{~min}$ at $25 \mathrm{rpm}$. Hardness of tablets was tested on 10 tablets using a Dr. Schleuniger Pharmaton 8M hardness tester (Switzerland). The same hardness tester was used for measuring diameter and thickness of the same tablets. Then, tensile strength (T) was calculated from the fracture of tablets by diametral compression as described in equation $5[11,12]$,

$\mathrm{T}=2 \mathrm{P} / \pi \mathrm{Dt}$

where $P$ is the applied load, and $D$ and $t$ represent the applied diameter and thickness of the tablet, respectively.

Disintegration time of outer layers of double-layer tablets was determined on 6 tablets in $750 \mathrm{~mL}$ $0.1 \mathrm{~N} \mathrm{HCl}$ solution at $37 \pm 0.5{ }^{\circ} \mathrm{C}$ constant temperature according to the method reported in USP 32. For this purpose, a Sotax DT2 disintegration apparatus (Switzerland) was used.

\section{Validation of analytical method for quantifica- tion of LRX}

Phosphate buffer solution at pH 7.4 (PBS pH 7.4) was decided to be used as the dissolution medium for in vitro release experiments since intestine is the main track for absorption of drugs in oral modified release dosage forms. Thus, the analytical method for quantification of drug by UV spectroscopy was obtained by dissolving LRX in PBS pH 7.4, validated and verified for linearity, intra-day and inter-day precision, accuracy, recovery and specificity [13].

Standard linear regression analysis was made in order to find out linearity of the quantification method. For this purpose, 2, 4, 6, 8, 10 and 12 $\mu \mathrm{g} \mathrm{mL}^{-1}$ standard LRX solutions in PBS $\mathrm{pH} 7.4$ were prepared by proper dilutions of a $1000 \mu \mathrm{g}$ $\mathrm{mL}^{-1}$ stock LRX solution. Absorbance of standard solutions was measured using a UV spectrophotometer (Shimadzu UV-1700 Japan) at $376 \mathrm{~nm}$. A calibration curve was constructed by plotting concentration versus absorbance. This study was replicated 6 times.

Intra-day repeatability and inter-day intermediate precision, and accuracy of quantification method were calculated from data obtained during a 5day validation. Six LRX solutions in PBS $\mathrm{pH} 7.4$ $\left(2,4,6,8,10\right.$ and $\left.12 \mu \mathrm{g} \mathrm{m}^{-1}\right)$ was prepared by proper dilutions of the stock solution $(1000 \mu \mathrm{g}$ $\mathrm{mL}^{-1}$ ) six times on the same day. Intermediate precision was assessed by comparing the assays on different days ( 5 days, $n=3$ at each concentration). Relative standard deviation (RSD, \%) obtained gave the precision when accuracy was expressed as the mean relative error (RME, \%).

Recovery of the method was found by the standard addition technique. For this purpose, a known amount of standard was added to the preanalysed sample at 4 different levels. The recovery (\%) was calculated using equation 6 .

Recovery $(\%)=\left(\mathrm{C}_{\mathrm{t}}-\mathrm{C}_{\mathrm{u}}\right) / \mathrm{C}_{\mathrm{a}} \times 100$

where $\mathrm{C}_{t}$ is the total concentration of the analyte found, $\mathrm{C}_{\mathrm{u}}$ concentration of the analyte present in the formulation, $\mathrm{C}_{\mathrm{a}}$ is the concentration of the pure analyte added to the formulation.

Specificity of the method was assayed for investigating whether excipients used for formulations interfered with quantification of LRX or not. Placebos of LRX formulations represented in Table 1 were prepared. Each of placebo double-layer tablets was powdered separately in a mortar. Powder $(0.5 \mathrm{~g})$ was weighed into a $25 \mathrm{~mL}$ volumetric flask to which $10 \mathrm{~mL}$ of PBS pH 7.4 was added and the mixture was kept in an ultrasonic bath for $15 \mathrm{~min}$. The mixture was filtered through a $S \& S^{5893}$ blue ribbon filter paper (Schleicher und Schuell, Germany) after being diluted to $25 \mathrm{~mL}$ with additional medium. Supernatant $(1 \mathrm{~mL})$ was withdrawn and diluted properly final solution was 
assayed by UV spectroscopy. Each study was replicated 6 times.

\section{In vitro release study}

Drug release from tablet cores and double-layer tablets was studied according to the USP 32 Method II (paddle) at $37 \pm 0.5^{\circ} \mathrm{C}$ in $900 \mathrm{~mL}$ PBS $\mathrm{pH} 7.4$ at $50 \mathrm{rpm}$ rotation speed. Samples $9 \mathrm{~mL}$ were taken from dissolution medium at predetermined time intervals. They were diluted to $10 \mathrm{~mL}$ and filtered through ablue ribbon filter paper. They were assayed by UV spectroscopy at $376 \mathrm{~nm}$.

Drug release profiles from tablet cores and double-layer tablets was evaluated using different kinetic models. Eqs. 7 - 9 describe zeroorder, first-order and Higuchi root-square models as follows $[14,15]$,

$Q_{t}=Q_{0}+k_{0} t$

where $Q_{t}$ and $Q_{0}$ are amount of drug released at time $\mathrm{t}$ and in the dissolution medium at $\mathrm{t}=0$ (usually, $Q_{0}=0$ ), respectively, and $k_{0}$ is the zeroorder release constant.

$Q_{t}=Q_{\infty}\left(1-e^{-k}{ }_{1}^{t}\right)$

where $Q_{\infty}$ represents the total amount of drug in the matrix and $k_{1}$ is the first-order kinetic constant.

Qt $=k_{H} t^{1 / 2}$

where $\mathrm{k}_{\mathrm{H}}$ is the Higuchi rate constant.

Drug release profiles were also evaluated using Korsmeyer-Peppas equation (exponential equation) (Eq. 10) since these models could fail to explain drug release mechanism in case of swelling along with gradual erosion of the matrix due to hydration [16],

$\log \left[Q_{t} / Q_{\infty}\right]=\log k+n \log t$

Swelling and erosion behaviours of tablet cores were investigated after immersion of the tablets in the dissolution medium PBS $\mathrm{pH}$ 7.4. Thus, relationship between drug release and polymer hydration could be clarified [17]. Tablets were weighed $\left(\mathrm{W}_{0}\right)$ and placed in beakers each containing a mesh underneath the tablets in PBS $\mathrm{pH}$ 7.4. Beakers were closed and placed a waterbath (Daihan Scientific, Korea) kept at $37 \pm$ $0.5{ }^{\circ} \mathrm{C}$ constant temperature during the study. After 1, 2, 3, 4, 5, 6, 7, 8, 9, 10 and 24 hours, beakers were removed from the water bath. Tablets with meshs were withdrawn from the medium and blotted to remove excess water and the tablets weighed $\left(\mathrm{W}_{1}\right)$. Wet samples were kept in a climatic test cabinet (Nüve TK 120, Turkey) at $80{ }^{\circ} \mathrm{C}$ and $10 \%$ relative humidity for $24 \mathrm{~h}$ time period. They were then allowed cooling in a desiccator and weighed until constant weights were achieved for each of them. Thus, final dry weight $\left(\mathrm{W}_{2}\right)$ of each sample was obtained. The experiment was performed in triplicate for each time point. Increase in weight due to absorbed liquid or medium uptake was estimated at each time point from Eq. 11 when remained \% of tablets at the 24th hour was calculated using Eqs 12 and 13.

Weight change $(\%)=\left[\left(W_{1}-W_{2}\right) / W_{0}\right] \times 100 \ldots \ldots . .(11)$

Remained $\%=100-$ ES

$E S=\left[\left(W_{0}-W_{2}\right) / W_{0}\right] \times 100$

\section{Statistical analysis}

In vitro drug release data were evaluated using GraphPad Prism 5 software and one-way ANOVA to determine differences for release profiles, swelling and erosion data of all formulations at 0.05 as the level of significance.

\section{RESULTS}

\section{Physical properties of LRX double-layer tablets}

$\mathrm{Cl}$ in the ranges of 12-16 and 18-21 displays respectively good and fair to passable flowability. Hausner ratio of a powder below 1.25 indicates good flowability, while above 1.6 predicts cohesion of particles [10]. Thus, $\mathrm{Cl}$ values and Hausner ratios give information on flowability and compressibility of powder mixtures of outer layer and tablet cores (Table 2). The result of physical characteristics of tablet cores and double-layer tablets provided good weight uniformity indicating low standard deviations up to \pm 1.2 (relative standard deviations lower than $0.5 \%$ ) as can be seen in Table 2. Hardness of tablet cores and double-layer tablets ranges from 106-200 $\mathrm{N}$ and 78-147 N, respectively. The lowest hardness values led to the lowest tensile strength. Tablet cores passed the friability test with values lower than $0.5 \%$ while the highest friability was obtained as $1.0 \%$, which is an acceptable value according to the compendial sources in the case of double-layer tablets. Outer layers of all doublelayer tablets disintegrated within $45 \pm 0.016 \mathrm{~s}$. 
Table 2: $\mathrm{Cl}$ values and hausner ratios of powder mixtures and physical characterization of LRX double-layer tablets

\begin{tabular}{|c|c|c|c|c|c|c|}
\hline \multicolumn{2}{|c|}{ Formulations } & $\begin{array}{c}\mathrm{Cl} \text { (Flow and } \\
\text { compression quality) }\end{array}$ & $\begin{array}{l}\text { Hausner } \\
\text { ratio }\end{array}$ & $\begin{array}{l}\text { Weight } \\
\text { (mg) }\end{array}$ & $\begin{array}{l}\text { Hardness } \\
\text { (N) }\end{array}$ & $\begin{array}{c}\text { Tensile } \\
\text { strength } \\
\text { (T) (Mpa) }\end{array}$ \\
\hline \multicolumn{2}{|c|}{ Outer layer } & $16.22(\mathrm{Good})$ & 1.19 & - & - & - \\
\hline & core HPMC-1 & 20.09 (Fair to passable) & 1.25 & $102 \pm 0.2$ & $106 \pm 3.92$ & $5.22 \pm 0.10$ \\
\hline $\mathscr{d}$ & core HPMC-2 & $16.75(\mathrm{Good})$ & 1.20 & $101 \pm 0.2$ & $106 \pm 2.94$ & $5.13 \pm 0.07$ \\
\hline ১ั & core PVP-1 & 33.34 (Poor) & 1.50 & $102 \pm 0.2$ & $111 \pm 3.91$ & $5.53 \pm 0.10$ \\
\hline \pm & core PVP-2 & 31.58 (Poor) & 1.46 & $103 \pm 0.2$ & $111 \pm 3.92$ & $5.31 \pm 0.11$ \\
\hline \multirow{2}{*}{$\begin{array}{l}\frac{\Phi}{0} \\
\frac{\widetilde{\sigma}}{\vdash}\end{array}$} & core Ca-1 & 34.99 (Poor) & 1.54 & $102 \pm 0.2$ & $200 \pm 8.88$ & $9.79 \pm 0.43$ \\
\hline & core Ca-2 & 34.88 (Poor) & 1.54 & $102 \pm 0.2$ & $178 \pm 5.88$ & $8.84 \pm 0.29$ \\
\hline \multirow{10}{*}{ 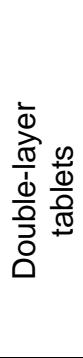 } & core HPMC-PVP-1 & 21.28 (Fair to passable) & 1.27 & $101 \pm 0.2$ & $123 \pm 2.94$ & $5.99 \pm 0.14$ \\
\hline & core HPMC-PVP-2 & 17.45 (Good) & 1.21 & $101 \pm 0.3$ & $125 \pm 2.82$ & $6.05 \pm 0.14$ \\
\hline & HPMC-1 & - & - & $249 \pm 1.2$ & $78 \pm 3.91$ & $2.01 \pm 0.10$ \\
\hline & HPMC-2 & - & - & $248 \pm 0.5$ & $93 \pm 3.92$ & $2.41 \pm 0.10$ \\
\hline & PVP-1 & - & - & $249 \pm 0.6$ & $86 \pm 5.89$ & $2.22 \pm 0.12$ \\
\hline & PVP-2 & - & - & $250 \pm 0.9$ & $90 \pm 4.91$ & $2.33 \pm 0.10$ \\
\hline & $\mathrm{Ca}-1$ & - & - & $249 \pm 0.6$ & $147 \pm 7.85$ & $3.82 \pm 0.20$ \\
\hline & $\mathrm{Ca}-2$ & - & - & $248 \pm 0.5$ & $140 \pm 4.91$ & $3.61 \pm 0.13$ \\
\hline & HPMC-PVP-1 & - & - & $248 \pm 0.5$ & $99 \pm 5.88$ & $2.55 \pm 0.15$ \\
\hline & HPMC-PVP-2 & - & - & $249 \pm 0.8$ & $91 \pm 2.93$ & $2.33 \pm 0.08$ \\
\hline
\end{tabular}

\section{Validation results}

Absorption spectra of LRX showed $\lambda_{\max }$ at 376 $\mathrm{nm}$. The representative linear equation was $A=$ $a C+b$, where $C$ is the concentration, $A=$ the absorbance, $\mathrm{a}=$ the slope, and $\mathrm{b}$ is the intercept. In the current method, regression equations were $\mathrm{A}=22.894 \mathrm{C}-0.078$ with $\mathrm{r}=0.9999$ in $\mathrm{PBS} \mathrm{pH}$ 7.4 .

Intra-day and inter-day R.S.D. values obtained by the proposed method were found to be between $0.40-1.90 \%$. Accuracy of the method was also expressed here as R.M.E. lower than 2 $\%$, between $0.08 \%$ and $1.67 \%$. Recovery of LRX was found between $99.77 \% \pm 0.002$ and $100.45 \% \pm 0.002$ by standard addition method.

Quantification method was specific for LRX detection. Constituents in formulations did not display absorbance at $376 \mathrm{~nm}$ which was the maximum wavelength for LRX in PBS pH 7.4.

\section{In vitro drug release}

Fast-disintegrating outer layer of all double-layer tablets released their LRX content within $45 \mathrm{~min}$ $(p>0.05)$. This is similar to the release profile obtained in the conventional tablet containing the individual dose of the drug (Figure 2a,b). Subsequently, tablets displayed sustained drug delivery since their tablet cores released drug in a longer time period. Statistically significant differences were detected among LRX release profiles obtained from tablet cores of all formulations $(p<0.05)$. The slowest LRX release rate $\left(1.21 \mathrm{mg} \% \cdot \mathrm{h}^{-1}\right)$ was obtained with double- layer tablets based on PVP K90 in the tablet core (formulations PVP-1 and PVP-2) followed by formulations HPMC-2 $\left(2.31 \mathrm{mg} \% \cdot \mathrm{h}^{-1}\right)$, HPMCPVP-2 (2.38 mg\%.h $\left.{ }^{-1}\right)$, HPMC-1 (2.80 $\left.\mathrm{mg} \% \cdot \mathrm{h}^{-1}\right)$, HPMC-PVP-1 $\left(2.89 \quad \mathrm{mg} \% \mathrm{~h}^{-1}\right), \quad \mathrm{Ca}-2 \quad(3.21$ $\left.\mathrm{mg} \% \cdot \mathrm{h}^{-1}\right)$ and Ca-1 $\left(3.26 \mathrm{mg} \% \mathrm{~h}^{-1}\right)$. Double-layer tablets released LRX according to Higuchi kinetic model (Table 3).

\section{Swelling and erosion behaviour of tablet cores}

As can be seen in Figure 1, the highest swelling rate was observed with carbomer based tablet cores (Ca-2 and $\mathrm{Ca}-1)$ followed by formulations HPMC-PVP-2, HPMC-PVP-1, HPMC-1, HPMC2, PVP-1 and PVP-2 $(p<0.05) .52 .75$ and 52.01 $\%$ of carbomer based tablet cores were remained at the end of $24 \mathrm{~h}$ indicating diffusion governed by Fick's law of Case II transport (Figure 3).

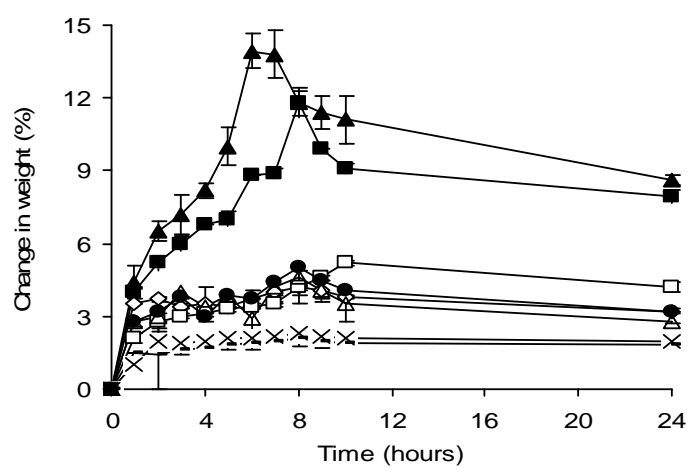

Figure 1: Change in weight of tablet cores for $24 \mathrm{~h} ; \diamond$ = core HPMC-1, $\square=$ core HPMC-2, $\mathrm{x}=$ core PVP-1, = core PVP-2, $\boldsymbol{\Delta}=$ core $\mathrm{Ca}-1, \mathbf{\square}=$ core $\mathrm{Ca}-2, \Delta=$ core HPMC-PVP-1, $\bullet=$ core HPMC-PVP-2.

Trop J Pharm Res, September 2015; 14(9): 1663 
a

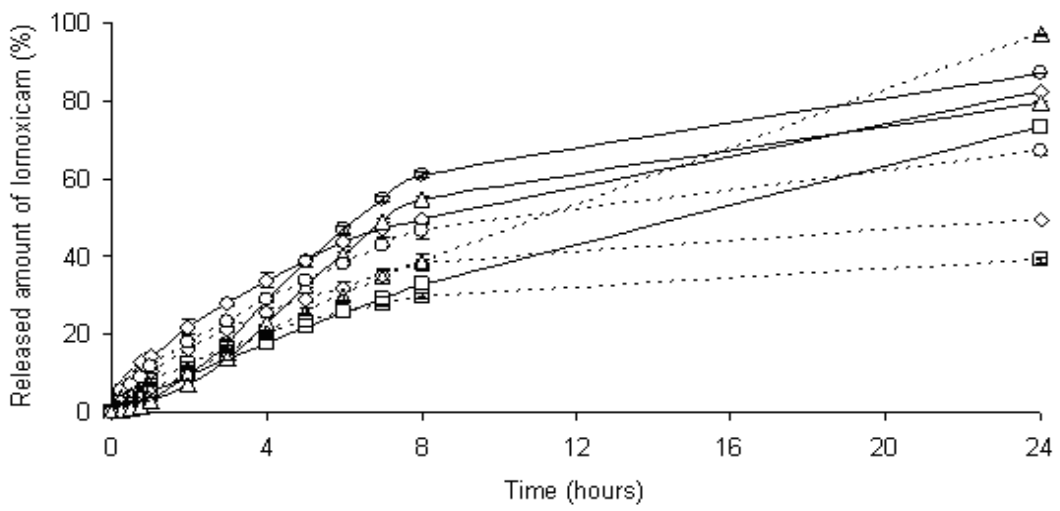

b

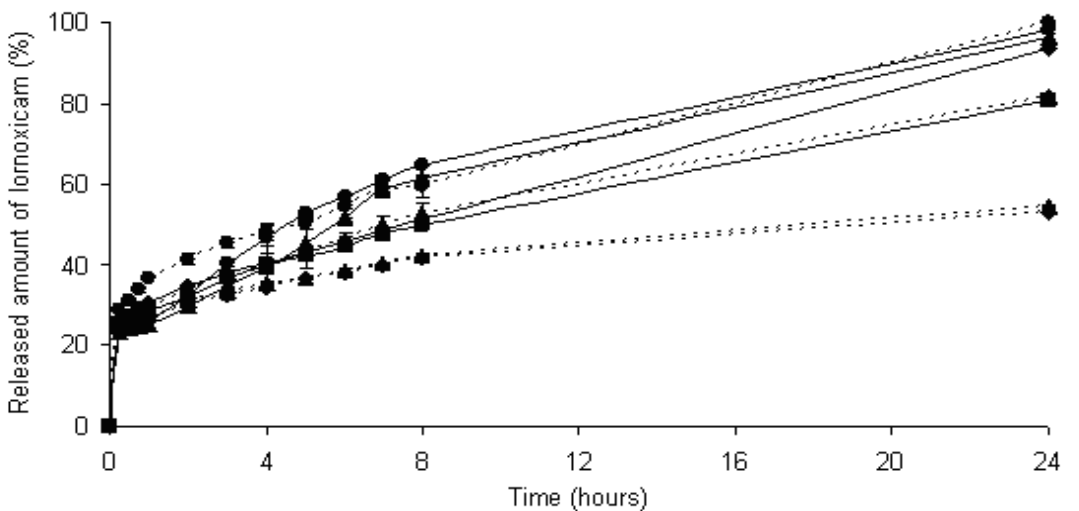

Figure 2a,b: Release profiles of LRX from tablet cores and their double-layer tablets. Figure 2a; $-\checkmark-=$ core HPMC-1, - - - = core HPMC-2, -- $---=$ core PVP-1, --口-- = core PVP-2, -०- = core Ca-1, $-\Delta-=$ core Ca-2, -- $---=$ core HPMC-PVP-1, -- $--=$ core HPMC-PVP-2, Figure $2 \mathbf{b} ;---=$ HPMC-1, - $-\mathbf{-}=$ HPMC-2, $----=$ PVP-1, $--\square--=$

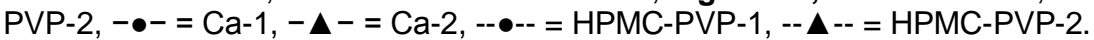

Table 3: Kinetic modeling of drug release from tablet cores and double-layer tablets

\begin{tabular}{|c|c|c|c|c|c|c|c|c|c|c|}
\hline \multirow[t]{2}{*}{ Formulation } & \multicolumn{2}{|c|}{$\begin{array}{l}\text { Zero } \\
\text { order }\end{array}$} & \multicolumn{2}{|c|}{ First order } & \multicolumn{2}{|c|}{$\begin{array}{l}\text { Higuchi } \\
\text { model }\end{array}$} & \multicolumn{2}{|c|}{$\begin{array}{c}\text { Exponential } \\
\text { (Korsmeyer - } \\
\text { Peppas model) }\end{array}$} & \multirow[t]{2}{*}{$\begin{array}{c}\text { Order of release } \\
\text { (Korsmeyer - } \\
\text { Peppas model) }\end{array}$} & \multirow[t]{2}{*}{$\begin{array}{l}\text { Diffusion } \\
\text { rate } \\
(\mathrm{g} / \mathrm{h}) \times 10^{3}\end{array}$} \\
\hline & $r$ & $K_{0}$ & $r$ & $K_{1}$ & $\boldsymbol{R}$ & $D$ & $r$ & $n$ & & \\
\hline \multicolumn{11}{|l|}{ Tablet cores } \\
\hline core HPMC-1 & 0.936 & 3.14 & 0.763 & 0.09 & 0.997 & 17.84 & 0.997 & 0.59 & Non-Fickian & 3.425 \\
\hline core HPMC-2 & 0.989 & 3.03 & 0.796 & 0.14 & 0.986 & 16.14 & 0.998 & 0.83 & Non-Fickian & 3.057 \\
\hline core PVP-1 & 0.857 & 1.90 & 0.698 & 0.09 & 0.968 & 11.45 & 0.986 & 0.61 & Non-Fickian & 2.065 \\
\hline core PVP-2 & 0.859 & 1.48 & 0.718 & 0.08 & 0.968 & 8.91 & 0.989 & 0.57 & Non-Fickian & 1.624 \\
\hline core $\mathrm{Ca}-1$ & 0.895 & 3.92 & 0.691 & 0.17 & 0.970 & 22.70 & 0.976 & 1.20 & Supercase II & 3.631 \\
\hline core Ca-2 & 0.904 & 3.61 & 0.695 & 0.18 & 0.970 & 20.62 & 0.980 & 1.27 & Supercase II & 3.314 \\
\hline $\begin{array}{l}\text { core } \\
\text { HPMC-PVP-1 }\end{array}$ & 0.904 & 2.62 & 0.752 & 0.09 & 0.986 & 15.21 & 0.992 & 0.60 & Non-Fickian & 2.790 \\
\hline $\begin{array}{l}\text { core } \\
\text { HPMC-PVP-2 }\end{array}$ & 0.996 & 3.99 & 0.842 & 0.13 & 0.972 & 20.79 & 0.983 & 0.77 & Non-Fickian & 4.014 \\
\hline \multicolumn{11}{|c|}{ Double-layer tablets } \\
\hline HPMC-1 & 0.996 & 2.80 & 0.951 & 0.05 & 0.976 & 14.65 & 0.947 & $\mathrm{n} / \mathrm{a}$ & $\mathrm{n} / \mathrm{a}$ & 3.905 \\
\hline HPMC-2 & 0.985 & 2.31 & 0.931 & 0.05 & 0.991 & 12.42 & 0.957 & $\mathrm{n} / \mathrm{a}$ & $\mathrm{n} / \mathrm{a}$ & 3.363 \\
\hline PVP-1 & 0.950 & 1.21 & 0.903 & 0.03 & 0.999 & 6.77 & 0.975 & $\mathrm{n} / \mathrm{a}$ & $\mathrm{n} / \mathrm{a}$ & 2.280 \\
\hline PVP-2 & 0.934 & 1.21 & 0.883 & 0.03 & 0.996 & 6.90 & 0.980 & $\mathrm{n} / \mathrm{a}$ & $\mathrm{n} / \mathrm{a}$ & 2.220 \\
\hline Ca-1 & 0.944 & 3.26 & 0.849 & 0.06 & 0.994 & 18.33 & 0.974 & $\mathrm{n} / \mathrm{a}$ & $\mathrm{n} / \mathrm{a}$ & 4.085 \\
\hline $\mathrm{Ca}-2$ & 0.966 & 3.21 & 0.891 & 0.06 & 0.987 & 17.51 & 0.952 & $\mathrm{n} / \mathrm{a}$ & $\mathrm{n} / \mathrm{a}$ & 4.020 \\
\hline HPMC-PVP-1 & 0.984 & 2.89 & 0.922 & 0.05 & 0.991 & 15.56 & 0.969 & $\mathrm{n} / \mathrm{a}$ & $\mathrm{n} / \mathrm{a}$ & 4.167 \\
\hline HPMC-PVP-2 & 0.976 & 2.38 & 0.914 & 0.05 & 0.995 & 12.93 & 0.967 & $\mathrm{n} / \mathrm{a}$ & $\mathrm{n} / \mathrm{a}$ & 3.405 \\
\hline
\end{tabular}




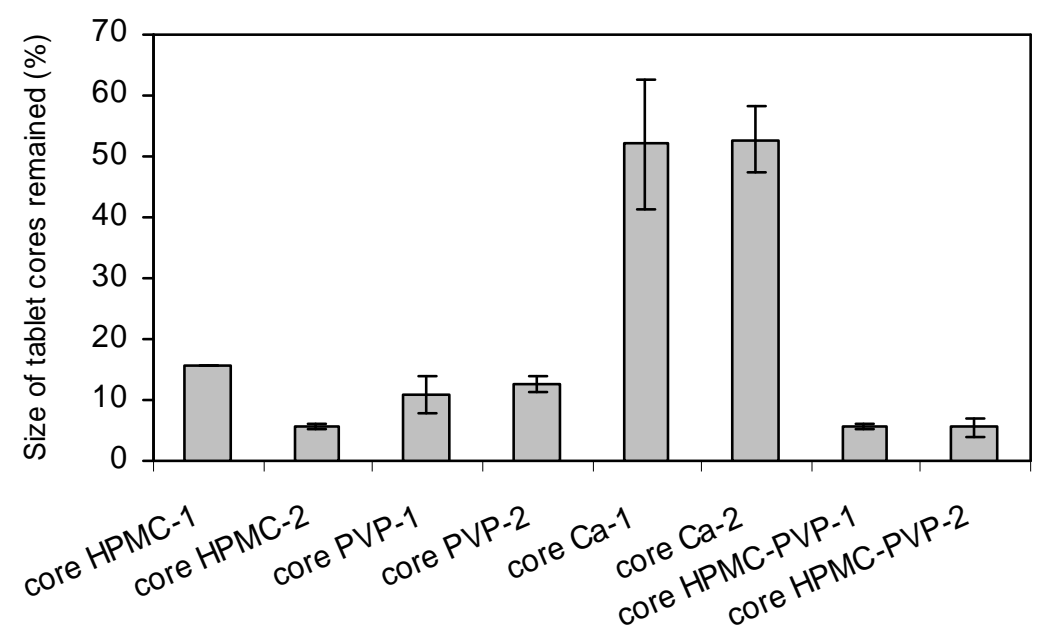

Figure 3: Size of tablet cores remaining at the 24th $\mathrm{h}$

\section{DISCUSSION}

The physical characteristics of the double-layer tablet formulations conformed to compendial requirements. Parameters describing physical properties of tablets demonstrated mechanical strengths of formulations. In spite of poor compression characteristics of core tablets based on PVP K90 and carbomer, the doublelayer tablets displayed good inter-layer adhesion as expected.

The outer layer of double-layer tablets displayed a good flow and compression characteristics when characteristics of tablet cores were variable depending on their polymer content (Table 2). Among the other polymers, carbomer caused the weakest compression quality for tablet cores (core Ca-1 and core Ca-2) indicating cohesion of powder particles and possible compression problems in a case of large scale production. PVP K90 followed carbomer with poor flow and compression quality of tablet cores (Formulations core PVP-1 and core PVP-2). Increase in concentrations of carbomer and PVP K90 did not affect the powder characteristics. However, HPMC and HPMC:PVP K90 mixture resulted in good or fair to passable flowability and compressibility all ratios in the formulations.

Increase in avicel concentration increased drug diffusion rate from tablet cores (Table 3 ). Carbomer based tablet cores (core $\mathrm{Ca}-1$ and core Ca-2) displayed Supercase II transport, which is typical for cylindrical matrix tablets indicating coupled diffusion/polymer relaxation, when the other formulations released drug in the non-Fickian kinetic correspond to coupled diffusion/erosion. When a matrix tablet containing hydrophilic polymers for sustaining drug release gets in contact with an aqueous medium, the medium passes into the matrix tablet structure and polymer at surface turns into a gel at first $[10,14]$. In the case of carbomer based tablet cores, system swelled by continuous medium transfer into tablets. Diffusion was governed by Fick's law and supercase II transport which reflects the influence of polymer relaxation on molecules' movement in the matrix, here $[18,19]$. However, tablet erosion follows polymer relaxation via the lost of the outer gel layer in the case of non-Fickian drug release. In other words, transfer of the dissolution media into the system continues and outer gel layer starts to regenerate followed by tablet erosion.

Swelling and erosion experiments on tablet cores also helped us describing drug release characteristics of tablets. Polymer relaxation and matrix swelling in carbomer based tablet cores (core $\mathrm{Ca}-1$ and core $\mathrm{Ca}-2$ ) are clearly reflected by Figures 2 and 3 . Swelling of those tablet cores reached to a maximum at the 8th $\mathrm{h}$ and they could maintained about $52 \%$ of their size at the 24th $\mathrm{h}$ indicating Supercase II transport as the dominant drug release mechanism. However, tablet erosion was detected with the tablet cores of other formulations displaying remaining percentage lower than $16 \%$ after $24 \mathrm{~h}$.

\section{CONCLUSION}

Double-layer tablets particle for tablet cores based on HPMC and HPMC-PVP mixture displayed better flow and compression properties while the slowest drug release profiles were obtained with PVP K90 based tablet cores. Although, PVP K90 and carbomer based tablet cores displayed poor flow and compression properties indicating possible problems for largescale production, double-layer tablets of all formulations showed desired physical 
characteristics. Outer layer and tablet cores of all formulations displayed adequate adhesive properties. It was concluded that double-layer tablets designed in this study could be used in the treatment of inflammatory conditions reducing frequency of dosing and providing patience compliance to the therapy.

\section{ACKNOWLEDGEMENT}

Two parts of this study were presented as posters in 6th World Meeting on Pharmaceutics, Biopharmaceutics and Pharmaceutical Technology (Barcelona, Spain, 7 - 10 April 2008) and 7th World Meeting on Pharmaceutics, Biopharmaceutics and Pharmaceutical Technology (Valetta, Malta, 8-11 March 2010). The first part was supported by Research Fund of Istanbul University (Project no. UDP2081/06022008).

\section{REFERENCES}

1. Leucuta SE. Drug delivery systems with modified release for systemic and biophase bioavailability. Curr Clin Pharmacol 2012; 7(4): 282-317.

2. Lamoudi L, Chaumeil JC, Daoud K. Development of gastro intestinal sustained release tablet formulation containing acryl-EZE and $\mathrm{pH}$-dependent swelling HPMC K 15 M. Drug Dev Ind Pharm 2012; 38(5): 515-520.

3. Maggi L, Machiste EO, Torre ML, Conte U. Formulation of biphasic release tablets containing slightly soluble drugs. Eur J Pharm Biopharm 1999; 48(1): 37-42.

4. Du Choi H, Kim KH, Park JS, Jeong SH, Park K. Evaluation of drug delivery profiles in geometric three-layered tablets with various mechanical properties, in vitro-in vivo drug release, and Raman imaging. J Control Release 2013; 172(3):763-772.

5. Conte $U$, Giunchedi $P$, Maggi L, Sangalli ME, Gazzaniga A, Colombo $P$, La Manna A. Ibuprofen delayed release dosage forms: $A$ proposal for the preparation of an in vitro/in vivo pulsatile system. Eur J Pharm Biopharm 1992; 38(6): 209-212.

6. Lopes CM, Lobo JMS, Pinto JF, Costa PC. Compressed matrix core tablet as a quick/slow dual-component delivery system containing ibuprofen.AAPS PharmSciTech 2007; 8(3): E195-E202.
7. Bröll $H$, llias W. Lornoxicam. Das Magazin für die Führungskräfte im Krakenhaus, 2004.

8. Martindale: The Complete Drug Reference, ed 35. London: The Pharm Pres, 2007.

9. Carr RL. Evaluating flow properties of solids. Chem Eng 1965; 18: 163-168.

10. Yener G, Naser A, Üner M, Barla A. Design of double layer tablets of valethamate bromide by using various polymers by direct compression method. Farmacia 2012; 60(5): 721-739.

11. Muzíková J, Vyhlídalová B, Pekárek T. A study of micronized poloxamers as lubricants in direct compression of tablets. Acta Pol Pharm 2013; 70(6): 1087-1096.

12. Summers MP, Enever RP, Carless JE. Influence of crystal form on tensile strength of compacts of pharmaceutical materials. J Pharm Sci 1977; 66(8): 1172-1175.

13. ICH Harmonised Tripartite Guideline. Validation of Analytical Procedures: Text and methodology Q2 (R1), 2005.

14. Higuchi T. Mechanism of sustained - action medication. Theoretical analysis of rate of release of solid drugs dispersed in solid matrices. J Pharm Sci 1963; 52: 1145-1149.

15. Panomsuk SP, Hatanaka $T$, Aiba $T$, Katayama $K$, Koizumi T. A study of the hydrophilic cellulose matrix: Effect of indomethacin and a water-soluble additive on release mechanisms. Chem Pharm Bull 1995; 43(6): 994-999.

16. Korsmeyer RW, Gurny R, Doelker E, Buri P, Peppas NA. Mechanisms of potassium chloride release from compressed, hydrophilic, polymeric matrices: effect of entrapped air. J Pharm Sci 1983; 72(10): 1189-1191.

17. Yin X, Li H, Guo Z, Wu L, Chen F, de Matas $M$, Shao $Q$, Xiao T, York $P, \mathrm{He} Y$, Zhang J. Quantification of swelling and erosion in the controlled release of a poorly water-soluble drug using synchrotron $x$-ray computed microtomography. AAPS J 2013; 15 (4) 1025-1034.

18. Enscore $D$, Hopfenberg $H$, Stannett $V$. Effect of particle size on the mechanism controlling $n$-hexane sorption in glassy polystyrene microspheres. Polymer 1977; 18(8): 793-800.

19. Kosmidis K, Rinaki E, Argyrakis $P$, Macheras $P$. Analysis of Case II drug transport with radial and axial release from cylinders. Int J Pharm 2003; 254(2): 183-188. 